UNIVERSIDADE FEDERAL DO RIO GRANDE DO SUL PÓS-GRADUAÇÃO EM PRODUÇÃO, TECNOLOGIA E HIGIENE DE ALIMENTOS DE ORIGEM ANIMAL

DETERMINAÇÃO DA PRESENÇA DE Salmonella spp EM CARCAÇAS SUÍNAS AO ABATE

Elaborado por: Karoline Sepanhack Urbano Aluna de Pós-Graduação em Produção, Tecnologia e Higiene de Alimentos de Origem Animal

Porto Alegre 
UNIVERSIDADE FEDERAL DO RIO GRANDE DO SUL ESPECIALIZAÇÃO EM PRODUÇÃO, TECNOLOGIA E HIGIENE DE ALIMENTOS DE ORIGEM ANIMAL

\title{
DETERMINAÇÃO DA PRESENÇA DE Salmonella spp EM CARCAÇAS SUÍNAS AO ABATE
}

\author{
Autor: Karoline Sepanhack Urbano \\ Monografia apresentada à \\ Faculdade de Veterinária como \\ requisito parcial para obtenção \\ do grau de Especialista em Produção, \\ Tecnologia e Higiene de Alimentos de \\ Origem Animal
}

Orientador: Dra. Verônica Schmidt Co-orientador: Dr. Sérgio Oliveira 


\section{AGRADECIMENTOS}

Agradeço à Deus pela acolhida e por estar sempre ao meu lado. Aos meus Pais, pessoas incríveis que estão ao meu lado, desde o meu nascimento, me apoiando qualquer "loucura" que queira fazer, apostando em minhas decisões e me incentivando em que tudo possa acontecer, basta ter persistência, força e confiança.

Agradeço à minha Irmã Kamila (Bucho) que, mesmo morando fora do Brasil, demonstrou-se prestativa. Ao meu amigo Gustavo (Gus) que me ajudou na montagem da monografia, pessoa bondosa e muito paciente. Aos meus amigos, que me apoiaram e se disponibilizaram para qualquer necessidade.

Agradeço ao Professor Sérgio Oliveira, pela confiança depositada para inicialização do projeto, que me permitiu a coleta de dados para a concretização desta monografia. Agradecimento especial aos funcionários da Empresa que me receberam, acompanharam e acolheram de forma calorosa.

Agradeço à professora Verônica Schmidt, por aceitar o meu pedido de orientar-me; pessoa incrível, responsável, querida, amada. Verônica saiba que tens mais uma admiradora.

Por fim, aos meus Protetores Espirituais, que estão presente comigo, me fortalecem e me inspiram.

Muito Obrigada. 


\begin{abstract}
This study presents results of research applied to a Brazilian company which exports animal products, to determine the presence of Salmonella spp in half-carcasses of pigs in the final stage of its slaughtering. The methodological procedure employed is based on applying swabs in areas of $10 \mathrm{~cm} 2$ respectively on the gammon, loin and dewlap of three hundred halfcarcasses. Out of seven $(0,017 \%)$ samples collected in the regions of the gammon, loin and dewlap, the presence of Salmonella was detected. The low isolation of Salmonella in the cold carcasses indicates the good conduct of the technology in slaughtering in the refrigerator.
\end{abstract}

\title{
RESUMO
}

Este trabalho apresenta resultados de uma pesquisa aplicada em uma empresa brasileira exportadora de produtos de origem animal, para determinar a presença de Salmonella spp em meias carcaças de suínos na fase final do abate. O procedimento metodológico empregado constituiu-se na aplicação de suabes em áreas de $10 \mathrm{~cm}^{2}$ respectivamente no pernil, lombo e papada de trezentas meias carcaças. Determinou-se a presença de salmonelas em sete $(0,017 \%)$ amostras coletadas nas regiões: pernil, lombo e papada. O baixo isolamento de Salmonella nas carcaças resfriadas indica a boa condução da tecnologia de abate no frigorífico. 


\section{LISTA DE TABELAS}

Tabela 1- Ocorrência de Infecções de origem alimentar por Salmonella ......................... 12 


\section{LISTA DE ABREVIATURAS E SIGLAS}

ABIPECS - Associação Brasileira da Indústria Produtora e Exportadora de Carne Suína AGE - Assessoria de Gestão Estratégica

APPCC - Análise de Perigos e Pontos Críticos de Controle

AS - Ágar Sangue

- B. cereus - Bacillus cereus

BPF - Boas Práticas de Fabricação

BPW - Água Peptonada Tamponada

$\mathrm{C}^{\mathrm{o}}$ - graus celsius

C.botulinum_- Clostridium botulinum

CEE - Comunidade Econômica Européia

C. perfringens - Clostridium perfringens

CVS - Centro de Vigilância Sanitária

DTA'S - Doenças Transmitidas por Alimentos

E._coli-Escherichia coli

Embrapa - Empresa Brasileira de Pesquisa Agropecuária

EUA - Estados Unidos

EUR - Euro

$\mathrm{h}-$ Horas

ICMSF - Comissão Internacional de Especificações Microbiológicas para Alimentos

IDENT - Identificação

ISO - Organização Internacional para Uniformização

MAPA - Ministério da Agricultura Pecuária e Abastecimento

MC - Mac Conkey

Meio de SIM - Meio de Sulfito, indol e motilidade

MS - Ministério da Saúde

ONU - Organização das Nações Unidas

PCC'S - Pontos Críticos de Controle

POP - Procedimento Operacional Padrão

RDC - Resolução da Diretoria Colegiada

RIISPOA - Regulamento de Inspeção Sanitária e Industrial de Produtos de Origem Animal

RVS - Caldo Rappaport Vassiliadis Soja

S. - Salmonella 
S. aureus_-Staphylococcus aureus

SC - Santa Catarina

SGE - Sistema de Gestão Estratégica

SINDICARNE - Sindicato da Indústria de Carne e Derivados

SIPS - Sindicato das Indústrias de Produtos Suínos

SP - Espécie

SPP - Espécies

SVS - Secretaria de Vigilância em Saúde

UAN - Unidade de Alimentação e Nutrição

USDA - Departamento de Agricultura dos Estados Unidos

XLD - Xilose lisina desoxicolato 


\section{SUMÁRIO}

1 INTRODUÇÃ̃ ................................................................................................................................ 10

2. REVISÃO DE LITERATURA .................................................................................. 11

2.1 Salmonella e Segurança alimentar.............................................................................................11

2.2 Ocorrência de Infecções de origem alimentar por Salmonella ..................................... 12

2.3 Enfermidades de Origem Alimentar ............................................................................. 13

2.4 Importância da Salmonella na Cadeia Alimentar ........................................................... 14

2.4.1 Prevenção da Salmonelose ......................................................................................... 15

2.5 Evolução do Problema com Salmonelas ......................................................................... 16

2.6 Vacinação Como Medida de Controle de Salmonella spp em Suínos ......................... 17

2.7 Programas de Segurança Alimentar (APPCC) ................................................................ 17

2.8 Boas Práticas de Fabricação (Legislação e Documentos de Qualidade) ..................... 19

2.8.1 Portaria SVS/MS 1.428 (26/11/1993): Diretrizes para o Estabelecimento de Boas Práticas de Produção e Prestação de Serviços na Área de Alimentos

2.8.2 Portaria SVS/MS 326 (30/07/1997): Regulamento Técnico para as Condições Higiênico-Sanitárias e de Boas Práticas de Fabricação para os Estabelecimentos Produtores e Industrializadores de Alimentos

2.8.3 Portaria CVS-6 (10/03/1999): Regulamento Técnico para os parâmetros e critérios a respeito do controle higiênico-sanitário em estabelecimentos de alimentos 20

2.8.4 Resolução RDC 275 (21/10/2002): Regulamento Técnico de Procedimentos Operacionais Padronizados aplicados aos Estabelecimentos Produtores e Industrializadores de Alimentos e Lista de Verificação das Boas Práticas de Fabricação em Estabelecimentos Produtores e Industrializadores de Alimentos

2.8.5 Resolução RDC 216 (15/09/2004): Regulamento Técnico de Boas Práticas para Serviços de Alimentação

2.9 Tipos de Barreiras Sanitárias na Comercialização de Suídeos e Métodos Derivados .

2.9.1 Classificação das Barreiras Sanitárias

2.9.1.1 Barreiras Fixas

2.9.1.2 Barreiras Móveis

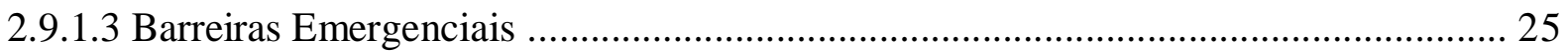

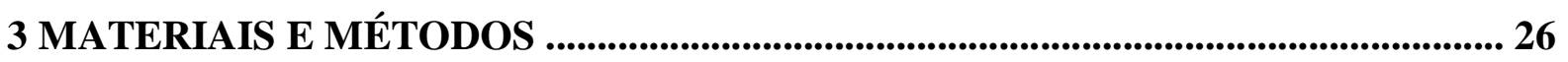

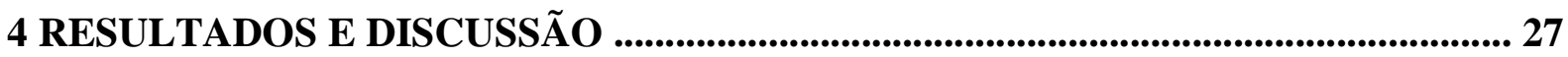


5 CONCLUSÃO

29

6 REFERÊNCIAS BIBLIOGRÁFICAS ........................................................................... 30 


\section{INTRODUÇÃO}

O suíno é reservatório para Salmonella spp, sendo as fezes e linfonodos as fontes de contaminação para carcaças em várias etapas do abate, citando-se a evisceração, toalete e a divisão da carcaça como os principais meios de introdução dos microerganismos.

A presença de portadores assintomáticos de Salmonella spp constitui-se em risco para a contaminação da carne e de produtos cárneos para consumo humano. Em situações onde há a entrada frequente de suínos positivos na linha de abate é difícil controlar a contaminação cruzada de carcaças, pois as medidas de sanitização pouco contribuem para redução dos índices de contaminação do produto final.

A industrialização, urbanização e especialização da produção mundial de alimentos, influenciam em uma série de transformações, como o surgimento de novas atividades e microrganismos mais resistentes. É necessário produzir o alimento mais seguro, com maior qualidade, garantia de certificações, não ocasionando riscos aos consumidores.

A fabricação de produtos cárneos aumentou significativamente nestas últimas décadas e, por esta causa, o animal que será abatido posteriormente deverá receber muitos cuidados em nível de granja.

Todas as medidas adotadas para que os alimentos apresentem condições sanitárias adequadas ao consumidor são muito importantes na saúde pública e animal, contribuindo para a prevenção e controle das doenças.

Este trabalho tem como objetivo determinar a contaminação de salmonella spp em meias carcaças nas seguintes porções: pernil, lombo e papada, na fase final do abate de suínos em um matadouro-frigorífico situado no Rio Grande do Sul. 


\section{REVISÃO DE LITERATURA}

\subsection{Salmonella e Segurança alimentar}

As salmoneloses podem estabelecer uma infecção, também no ser humano, que pode infectar-se no manejo com os animais ou apartir da manipulação de suínos abatidos em frigoríficos. O agente etiológico é um cocobacilo Gram negativo, móvel, do gênero salmonella, espécie S. entérica e da família Enterobacteriaceae. O suíno pode sofrer infecção por uma grande variedade de sorovares. Entretanto, a doença clínica tem sido descrita, principalmente, nas infecções pelas espécies S. Choleraesuis e S. Enteriditis sorovar Thyphimurium. Ocasionalmente outros sorovares da espécie S. Enteritidis, tais como: S. Thyphisuis, S. Dublin, S. Derby, S. Anatum e S. Newport, podem provocar a doença. Além desses, existem mais de 2.500 sorovares, alguns dos quais foram eventualmente responsabilizados como causadores de doença clínica em suínos.

O agente sobrevive durante meses no ambiente, suporta dessecação e congelamento, mas, é bastante sensível à luz solar e à maioria dos desinfetantes (fenóis, clorados e iodados). 


\subsection{Ocorrência de Infecções de origem alimentar por Salmonella}

A distribuição anual dos agentes etiológicos de Doenças transmitidas por alimentos (DTA`s) identificados em surtos investigados em Porto Alegre, no período de 2003 a 2011, é apresentado na Tabela 1.

Tabela 1: Número de surtos e representatividade (\%) dos agentes etiológicos de DTA's investigados em Porto Alegre, no período de 2003 a 2011.

\begin{tabular}{|c|c|c|c|c|c|c|c|c|c|c|c|}
\hline \multicolumn{12}{|c|}{ Ano } \\
\hline Agente & 2003 & 2004 & 2005 & 2006 & 2007 & 2008 & 2009 & 2010 & 2011 & Total & $\%^{1}$ \\
\hline Salmonella & 1 & 2 & 4 & 3 & 2 & 8 & 2 & - & 2 & 24 & 14 \\
\hline$\%$ & 10 & 13 & 19 & 16 & 9 & 26 & 10 & - & 7 & & \\
\hline E.coli & 1 & 1 & 3 & 2 & 1 & - & - & - & 1 & 9 & 5 \\
\hline$\%$ & 10 & 6 & 14 & 11 & 4 & - & - & - & 4 & & \\
\hline S.aureus & 3 & 3 & 3 & 1 & 4 & 4 & 1 & 1 & 4 & 24 & 14 \\
\hline$\%$ & 30 & 20 & 14 & 5 & 18 & 13 & 5 & 10 & 15 & & \\
\hline B.cereus & 1 & 2 & 3 & 6 & 3 & 5 & 3 & 1 & 5 & 29 & 16 \\
\hline$\%$ & 10 & 13 & 14 & 33 & 13 & 16 & 16 & 10 & 18 & & \\
\hline C.perfrigens & - & 2 & 1 & 2 & 4 & 6 & 4 & 2 & 3 & 24 & 14 \\
\hline$\%$ & - & 13 & 4 & 11 & 18 & 19 & 21 & 20 & 11 & & \\
\hline $\begin{array}{l}\text { Cl. } \text { botulinum } \\
(\mathrm{N})\end{array}$ & - & - & 1 & - & - & - & - & - & - & 1 & 0,5 \\
\hline$\%$ & - & - & 4 & - & - & - & - & - & - & & \\
\hline Listeria & - & - & - & - & 1 & - & - & - & - & 1 & 0,5 \\
\hline$\%$ & - & - & - & - & 4 & - & - & - & - & & \\
\hline Shigella & 1 & - & - & - & - & - & - & - & - & 1 & 0,5 \\
\hline$\%$ & 10 & - & - & - & - & - & - & - & - & & \\
\hline $\begin{array}{l}\text { Coliformes } \\
\text { termotolerantes }\end{array}$ & 1 & - & 1 & - & - & - & - & - & - & 2 & 1 \\
\hline$\%$ & 10 & - & 4 & - & - & - & - & - & - & & \\
\hline $\begin{array}{l}\text { Não } \\
\text { identificados }\end{array}$ & 2 & 5 & 5 & 4 & 7 & 8 & 9 & 6 & 12 & 58 & 33 \\
\hline$\%$ & 20 & 33 & 24 & 22 & 32 & 26 & 47 & 60 & 44 & & \\
\hline Total & 10 & 15 & 21 & 18 & 22 & 31 & 19 & 10 & 27 & 173 & 100 \\
\hline
\end{tabular}

Os dados revelam Salmonella spp como o segundo agente de maior ocorrência entre os surtos de DTA's investigados em Porto Alegre. 


\subsection{Enfermidades de Origem Alimentar}

As enfermidades de origem alimentar ocorrem quando uma pessoa contrai uma doença devido à ingestão de alimentos contaminados com microrganismos e/ ou toxinas indesejáveis. Essa condição é frequentemente denominada como toxinfecção alimentar. É sabido que apenas um pequeno número de casos de enfermidades causadas por alimentos são notificados aos órgãos de inspeção de alimentos, de controle e às agências de saúde. Isso se deve, em parte $_{2}$ ao fato de que muitos patógenos presentes em alimentos causam sintomas brandos; e a vítima não busca auxílio médico (FORSYTHE, 2002).

Condições sanitárias deficientes durante o abate dos animais, cozimento inadequado, armazenamento impróprio, e falta de higiene durante o preparo dos produtos cárneos são condições que podem predispor os indivíduos a tornarem-se portadores assintomáticos ou doentes. Dependendo do microrganismo envolvido, os sintomas podem variar de desconforto intestinal moderado a desidratação severa, ou diarreia hemorrágica e morte (PELCZAR, 1997).

A ausência nos alimentos de microrganismos patógenos para o homem e de suas toxinas constitui-se numa exigência primária: se pressupõe que os alimentos não transmitirão enfermidades aos consumidores. Além disso, os alimentos de boa qualidade microbiológica devem apresentar níveis reduzidos de microrganismos deteriorantes (BENITEZ, 2000).

A contaminação biológica de alimentos é um problema de saúde pública no Brasil, assim como afeta o mundo todo. No país existe normatização adequada para controle sanitário dos alimentos, como o Regulamento de Inspeção Industrial e Sanitária de Produtos de Origem Animal (RIISPOA), do Ministério da Agricultura Pecuária e Abastecimento (MAPA). Porém, ainda falta a fiscalização efetiva e permanente da produção, conservação e comercialização de alimentos pelos serviços estaduais e municipais de vigilância sanitária, aos quais é delegado o poder de inspecionar e punir os infratores (BALBANI \& BUTUGAN, 2001).

A qualidade da matéria-prima, a padronização do processamento e a manutenção das temperaturas na saída da indústria até as gôndolas do supermercado têm sido citadas como parâmetros importantes para se evitar as cada vez mais frequentes toxinfecções alimentares. A busca incessante da qualidade, seja na produção, transporte, armazenamento e consumo de alimentos é fator primordial na competição entre empresas deste mercado (RICHARDS, 2003). 


\subsection{Importância da Salmonella na Cadeia Alimentar}

Salmonelose é uma doença infecciosa provocada por um grupo de bactérias do gênero Salmonella, que pertencem à família Enterobacteriaceae, existindo muitos tipos diferentes desse microrganismo. Salmonella é conhecida há mais de 100 anos e o termo é uma referência ao cientista americano chamado Salmon, que descreveu a doença associada à bactéria pela primeira vez.

Salmonella é transmitida ao homem através da ingestão de alimentos contaminados com fezes animais. Os alimentos contaminados apresentam aparência e cheiro normais e a maioria deles é de origem animal, como carne de gado, suíno, frango, ovos e leite. Entretanto, todos os alimentos, inclusive vegetais, podem tornar-se contaminados. É muito frequente a contaminação de alimentos crus de origem animal e o cozimento destes elimina o microrganismo.

A manipulação de alimentos por pessoas contaminadas que não lavam as mãos com sabonete pode causar sua contaminação._A contaminação das mãos por microrganismos pode ter origem nas fezes de animais de estimação, especialmente os que apresentam diarreia, sendo que algumas espécies como os répteis são hospedeiros em potencial de Salmonella. Por este motivo deve-se estimular o hábito de lavar as mãos imediatamente após manusear animais, mesmo que este apresente-se clinicamente saudável.

A maior parte das pessoas infectadas com Salmonella apresenta diarreia, dor abdominal e febre. Estas manifestações iniciam de 12 a 72 horas após a infecção. A doença tem duração de 4 a 7 dias e a maioria das pessoas se recupera sem tratamento. Em algumas pessoas infectadas, a diarreia pode ser severa a ponto de ser necessária a hospitalização devido à desidratação.

Os idosos, crianças e aqueles com as defesas diminuídas (diminuição da resposta imune) são os grupos mais prováveis de ter a forma mais severa da doença. Uma das complicações mais graves é a difusão da infecção para o sangue e para outros tecidos, o que pode causar a morte caso a pessoa não seja rapidamente tratada.

Muitas doenças podem causar as mesmas manifestações que a salmonelose, sendo o diagnóstico, na maior parte das vezes, associado à história alimentar recente. A comprovação de que as manifestações clinicas sejam causadas por Salmonella só pode ser feita pela identificação do microrganismo nas fezes da pessoa infectada e é útil somente nos casos mais graves, em que a administração de antibiótico se faz necessária. Este teste usualmente não é realizado em um exame comum de fezes, sendo necessário uma instrução específica ao 
laboratório para a procura do agente nas fezes. Uma vez identificado pode ser realizada a cultura das fezes para a determinação do tipo específico e qual antimicrobiano deve ser utilizado para o tratamento.

A infecção por Salmonella usualmente tem duração de 5 a 7 dias e frequentemente não é necessário tratamento, sendo suficiente a utilização de medidas de suporte e conforto ao paciente. Após este período, a pessoa se recupera, podendo permanecer ainda por algum tempo um hábito intestinal irregular. Caso o paciente se torne severamente desidratado ou a infecção se difunda do intestino para outras regiões do organismo, medidas terapêuticas devem ser tomadas, incluindo a hospitalização. Pessoas com diarreia severa devem ser reidratadas através da administração endovenosa de soro. Os casos graves, em que a infecção se difunde, devem ser tratados com antimicrobianos.

\subsubsection{Prevenção da Salmonelose}

Para a prevenção da infecção por salmonelas pelos alimentos, citam-se medidas como:

- Sendo os alimentos de origem animal uma das principais fontes de contaminação por Salmonella, ovos e carnes, não devem ser ingeridos crus, mal-passados ou não completamente cozidos;

- Atenção especial deve ser dada aos ovos crus que aparecem sem serem percebidos em um grande número de pratos, como maionese caseira, molho holandês, tiramisu, sorvete caseiro. Estes pratos devem ser evitados;

- Carnes em geral, incluindo hambúrgueres e frango, devem ser bem cozidas (não devem estar avermelhadas no centro). Leite não pasteurizado deve ser evitado;

- Todos os produtos devem ser bem lavados antes de sua preparação e consumo;

- Contaminação entre alimentos deve ser evitada: carnes cruas devem ficar separadas de alimentos que estão sendo preparados, de alimentos já cozidos e de alimentos prontos para serem servidos;

- Todos os utensílios de cozinha (tábuas, facas, etc.) devem sempre ser lavados após sua utilização em alimentos crus;

- As mãos devem ser lavadas antes do manuseio de qualquer alimento e entre o manuseio de diferentes itens alimentares; 
- Já que os répteis são portadores em potencial da Salmonella, qualquer pessoa deve lavar as mãos imediatamente após o contato com estes animais;

- Répteis, incluindo as tartarugas, não são apropriados como animais de estimação de crianças e não deveriam habitar o mesmo ambiente.

\subsection{Evolução do problema com salmonelas}

No passado, os produtos de origem suína estiveram menos frequentemente implicados como fonte de surtos de infecção alimentar causados por Salmonella em humanos. Entretanto, após um surto ocorrido na Dinamarca, onde a fonte pode ser traçada até produtos suínos, a situação mundial tem se modificado (WEGENER \& BAGER, 1997). A partir deste evento, iniciou-se um programa de controle que passou a ser adotado pela maioria dos países produtores e exportadores de produtos suínos.

As carnes e seus derivados são alimentos bastante susceptíveis à contaminação por Salmonella sp. Este fato está relacionado à dificuldade de manter os lotes livres deste microrganismo no sistema vertical de produção e distribuição dos animais. Ao lado disso, o crescimento da participação de vegetais como fonte de infecção para humanos está sendo atribuída ao manejo das culturas, à exemplo da utilização de fertilizantes contaminados, ao processamento do produto e ao modelo globalizado de circulação dos alimentos entre os países (D’AOUST, 1994).

Nos EUA estima-se que são gastos cerca de U\$ 700 para cada caso de infecção por Salmonella em humanos. Na União Européia, calcula-se que a doença cause um custo anual de cerca de EUR 2,8 bilhões com medidas preventivas, curativas e de controle. Na América Latina, Salmonella sp foi a segunda maior causa de infecções veiculadas por alimentos no período de 1995 a 1998 (SANTOS et al., 2003).

Ainda é necessário determinar quais fatores de risco são importantes para as condições de manejo em nosso país, para que recomendações de controle sejam estabelecidas. Os fatores citados como importantes para o controle tem sido o estabelecimento de um programa de desinfecção eficiente associado ao vazio sanitário e o controle da ração (TIELEN et al. apud WEISS, 2002).

Thorberg \& Engvall (2001) relataram que os processos particularmente envolvidos no risco de contaminação por Salmonella sp no abate de suínos são a evisceração e a toalete, mas 
o escaldamento e a divisão da carcaça também podem introduzir microrganismos que resultam em uma maior contaminação ao fim da linha do abate.

O aumento da incidência de salmonelose está associado ao aumento da população, da criação e alimentação de animais com o uso de antimicrobianos e do consumo de carnes e derivados, à preparação maciça de alimentos, ao armazenamento inadequado e ao hábito crescente do consumo de produtos crus e mal cozidos (BARRETO, 2001).

\subsection{Vacinação como medida de controle de Salmonella spp em suínos}

Foi lançada em 2004, a primeira vacina viva avirulenta do mercado mundial contra a infecção por diversos tipos de salmonelas, principalmente a $S$. Choleraesuis e $S$. Typhimurium. A vacina contém uma amostra avirulenta de Salmonella, ou seja, um organismo vivo desenvolvido especialmente para não causar a doença nos suínos, mas que mantém sua capacidade de gerar imunidade e proteger contra infecções futuras. A nova vacina foi desenvolvida e testada na Universidade de Iowa nos EUA e passou por rigorosas avaliações, tanto em laboratório quanto em condições de campo. Os resultados demonstraram que a vacina é altamente eficaz na prevenção dos sinais clínicos causados pela infecção por Salmonella nos suínos, com consequente diminuição do nível de contaminação da carne produzida, além de ser extremamente segura e de fácil aplicação (KICH, 2004).

\subsection{Programas de Segurança Alimentar (APPCC)}

A prática de analisar microbiologicamente produtos finais tem sido realizada durante décadas. No entanto, a apreciação estatística da utilidade dessa prática tem sido amplamente revisada (FORSYTHE, 2002).

As análises microbiológicas, complementos das inspeções, são limitadas sob o ponto de vista estatístico, devido ao número de amostras que se deve coletar e analisar. Quando estes resultados ficam prontos, depois de alguns dias, os alimentos pesquisados já foram consumidos, ou enviados para outros estabelecimentos (IAMFES, 1991).

A Análise de Perigos e Pontos Críticos de Controle (APPCC) baseia-se numa investigação sistemática para identificar, avaliar e controlar os perigos advindos do processamento de alimentos nas linhas de produção, distribuição e consumo, para identificar 
alimentos altamente perigosos e que possam permitir o crescimento microbiano (ICMSF, 1997).

Almeida (1998) elucida que o sistema APPCC está embasado na aplicação de princípios técnicos e científicos na produção e manejo dos alimentos e que esta prática cobre todo tipo de fatores de riscos ou perigos potenciais à inocuidade dos alimentos: perigos biológicos, químicos e físicos, seja os que ocorrem de forma natural no alimento, no ambiente ou decorrentes de possíveis erros no processamento. Enquanto os perigos químicos são os mais temidos pelos consumidores e os perigos físicos, mais comumente identificados, os perigos biológicos são os mais sérios do ponto de vista de saúde pública.

A avaliação por análise de perigos em pontos críticos de controle é composta de sete etapas fundamentais. O primeiro passo é identificar os perigos potenciais associados à produção do alimento em todos os seus estágios: produção da matéria-prima (suíno, soja, etc.), manufatura, distribuição, etc. Em seguida, deve-se reconhecer os pontos críticos que podem ser controlados para eliminar os perigos ou minimizar a possibilidade de sua ocorrência, são estes os chamados pontos críticos de controle. Feito isso, a empresa/ fiscalização deve estabelecer os limites críticos, de contaminação, por exemplo, aceitáveis para um determinado produto.

As demais etapas são:

- Organizar um sistema para monitorar o controle dos pontos críticos por meio de testes ou observações pré-determinadas;

- Elaborar ações corretivas a serem tomadas pela área de produção sempre que o monitoramento indicar pontos críticos fora de controle;

- Criar procedimentos de verificação que abranjam testes suplementares e procedimentos para confirmar se o sistema está funcionando de maneira adequada;

- E, por fim, elaborar um histórico de produção por meio de documentação descritiva dos procedimentos executados na elaboração do produto (CONTRERAS, 1999).

A intenção da APPCC de enfocar as etapas que são PCC's (Pontos Críticos de Controle) é de grande interesse para a sanidade dos alimentos (TOMPKIN, 1994).

Em 1985, o Comitê da Academia Nacional de Ciência recomendou o uso do sistema APPCC em programas de proteção de alimentos, sugerindo que tanto as indústrias de alimentos como os órgãos governamentais fossem treinados nesse sistema (CONTRERAS, 2003). 
Desde 1991, o Comitê do Codex Alimentarius vem recomendando a utilização do APPCC por todos os países membros da ONU, evidenciando os benefícios consideráveis oferecidos, seja pela inocuidade e qualidade dos alimentos ou pela racionalização dos recursos e resposta mais oportuna aos problemas (ZANARDI, 2000).

O sistema APPCC passou a ser exigido nas indústrias de alimentos nos diferentes continentes (Diretiva 93/94/CEE), inclusive em nosso país, através da Portaria $\mathrm{n}^{\circ} 1428$ do Ministério da Saúde, de 26/11/93 (TERRA, 1998). Em 1997, o Ministério da Agricultura Pecuária e Abastecimento formalizou a adoção do sistema como mecanismo auxiliar do sistema clássico de inspeção industrial e sanitária dos produtos de origem animal (CONTRERAS, 2003).

Destro (1998) esclareceu que a existência de programas em empresas processadoras de alimentos que controlem as condições operacionais, mantendo um ambiente favorável para a produção de alimentos seguros, são pré-requisitos para a implantação da APPCC. Programas como Boas Práticas de Fabricação (BPF) e Procedimentos Operacionais Padrões de Sanitização (POP's) têm sido implantados em empresas de alimentos como pré-requisitos à implantação da APPCC.

\subsection{Boas práticas de Fabricação - Legislação e Documentos de Qualidade}

2.8.1 Portaria SVS/MS 1.428 (26/11/1993): Diretrizes para o Estabelecimento de Boas Práticas de Produção e Prestação de Serviços na Área de Alimentos

A portaria se aplica a todos os órgãos de vigilância sanitária nos níveis federal, estadual e municipal, nas atividades primárias, secundárias e terciárias em toda a cadeia alimentar.

Em relação às condições físicas dos estabelecimentos, essa portaria faz referência aos seguintes itens:

- Condições ambientais: recomendações sobre as condições internas e externas do ambiente e os procedimentos para controle sanitário de tais condições;

- Instalações e saneamento: recomendações sobre a planta baixa do estabelecimento, materiais de revestimento, instalações elétricas e hidráulicas, serviços básicos de saneamento e respectivos controles sanitários; 
- Equipamentos e utensílios: recomendações referentes aos equipamentos e utensílios utilizados nos processos tecnológicos e respectivos controles sanitários.

2.8.2 Portaria SVS/MS 326 (30/07/1997): Regulamento Técnico para as Condições Higiênico-Sanitárias e de Boas Práticas de Fabricação para os Estabelecimentos Produtores e Industrializadores de Alimentos

Esse regulamento estabelece os requisitos essenciais de higiene e de boas práticas de fabricação para alimentos produzidos e fabricados para o consumo humano.

Em relação à estrutura física, essa portaria faz referência e recomendações aos seguintes itens:

- Localização: recomendações sobre as características da área onde a UAN (Unidade de Alimentação e Nutrição) será construída;

- Vias de acesso interno: recomendações sobre a área utilizada para circulação pelo estabelecimento (tipo de pavimentação, escoamento de água adequado e controle de meios de limpeza);

- Edifícios e instalações: recomendações sobre o material de construção dos edifícios e instalações, fluxo, layout, materiais de revestimentos, portas e janelas, iluminação, ventilação e abastecimento de água;

- Equipamentos e utensílios: recomendações referentes aos equipamentos e utensílios utilizados nos processos tecnológicos e respectivos controles sanitários.

2.8.3 Portaria CVS-6 (10/03/1999): Regulamento Técnico para os parâmetros e critérios a respeito do controle higiênico-sanitário em estabelecimentos de alimentos

A portaria se aplica a todos os estabelecimentos nos quais sejam realizadas algumas das seguintes atividades: produção, industrialização, fracionamento, armazenamento e transporte de alimentos.

Em relação à estrutura física dos estabelecimentos, ela faz referência e recomendações detalhadas em relação aos seguintes itens:

- Estrutura e edificação: recomendações sobre a localização, materiais de revestimento para piso, paredes, forros e tetos, portas e janelas, iluminação, ventilação, instalações 
sanitárias, vestiário, lixo, esgotamento sanitário, setores de recepção, armazenamento, pré-preparo,preparo, consumo, administração e higienização;

- Equipamentos e utensílios: sobre dimensionamento, materiais de construção e acabamento;

- Sistema de exaustão/sucção: recomendações sobre materiais de construção e acabamento.

2.8.4 Resolução RDC 275 (21/10/2002): Regulamento Técnico de Procedimentos Operacionais Padronizados aplicados aos Estabelecimentos Produtores e Industrializadores de Alimentos e Lista de Verificação das Boas Práticas de Fabricação em Estabelecimentos Produtores e Industrializadores de Alimentos

Essa resolução se aplica aos estabelecimentos processadores e industrializadores nos quais sejam realizadas algumas das seguintes atividades: produção, industrialização, fracionamento, armazenamento e transporte de alimentos industrializados. Além disso, recomenda a aplicação de uma lista de verificação completa.

Em relação à estrutura física, por meio da lista de verificação,_essa resolução faz referência e recomendações detalhadas em relação aos seguintes itens:

- Edificações e instalações: recomendações para a área externa;_vias de acesso interno, área interna, incluindo recomendações para pisos, tetos, paredes e divisórias, portas, janelas e outras aberturas, escadas, elevadores de serviço, monta-cargas e estruturas auxiliares, instalações sanitárias e vestiários para manipuladores, instalações sanitárias para visitantes e outros, lavatórios na área de produção, iluminação e instalação elétrica, ventilação e climatização, barreiras físicas para controle integrado de vetores e pragas urbanas, abastecimento de água,área adequada para estocagem dos resíduos, esgotamento sanitário e leiaute.

- Equipamentos, móveis e utensílios: recomendações quanto aos materiais de construção e revestimento.

2.8.5 Resolução RDC 216 (15/09/2004): Regulamento Técnico de Boas Práticas para Serviços de Alimentação. 
Essa resolução se aplica aos serviços de alimentação que realizam algumas das seguintes atividades: manipulação, preparação, fracionamento, armazenamento, distribuição, transporte, exposição à venda e entrega de alimentos preparados ao consumo, tais como cantinas, bufês, comissárias, confeitarias, cozinhas industriais, cozinhas institucionais, delicatéssens, lanchonetes, padarias, pastelarias, restaurantes, rotisserias e congêneres.

Em relação à estrutura física, dos serviços de alimentação, essa resolução faz referência e recomendações aos seguintes itens:

- Edificação, instalação, equipamentos, móveis e utensílios:recomendações sobre o acesso, fluxo de atividades, materiais de revestimento para paredes, tetos e pisos, portas e janelas, iluminação,instalações elétricas, ventilação, instalações sanitárias e vestiários,superfícies de equipamentos, móveis e utensílios;

- Controle integrado de vetores e pragas urbanas: recomendações sobre as ações integradas para controle de vetores e pragas;

- Abastecimento de água: recomendações sobre o material de construção dos reservatórios de água;

- Manejo dos resíduos: recomendações sobre características dos coletores de resíduos e localização dos setores de lixo;

- Preparação do alimento: recomendações sobre o quantitativo de equipamentos, móveis e/ou utensílios, barreiras técnicas ou físicas, presença de lavatórios na área de produção, aquisição de equipamentos adequados, climatização no setor de pré-preparo de carnes;

- Exposição ao consumo do alimento preparado: recomendações sobre características de equipamentos, móveis ou utensílios;

- Armazenamento e transporte do alimento preparado:recomendações sobre as características do veículo para transporte de alimentos.

Para se estabelecer e executar um plano de boas práticas é indispensável que a estrutura física esteja de acordo com a legislação vigente e que o planejamento, a construção e as possíveis reformas da área de produção sejam baseadas nas atividades a serem desenvolvidas nesse serviço, bem como na especificação de equipamentos, móveis e utensílios.

As boas práticas consideram, de maneira geral, quatro pontos principais a serem analisados e utilizados:

- Pontos críticos de controle e práticas referentes a pessoal; 
- Instalações (áreas externas e internas, plantas físicas, ventilação e iluminação adequadas, controle de pragas, uso e armazenamento de produtos químicos, abastecimento de água, encanamento e coleta de lixo);

- Requisitos gerais de equipamentos (construção, facilidade de limpeza e manutenção);

- Controles de produção. 


\subsection{Tipos de Barreiras Sanitárias na Comercialização de Suídeos e Métodos Derivados}

O Ministério da Agricultura edita um conjunto de normas e regulamentos com o objetivo de conferir qualidade aos alimentos de origem animal, tanto durante o processamento, quanto nos estabelecimentos. Para o cumprimento dessas regras, são desenvolvidas ações de fiscalização, investigação, avaliação e auditagem.

\subsubsection{Classificação das Barreiras}

As barreiras sanitárias estão classificadas em barreiras fixas, podendo ser de caráter inter ou intraestadual, e barreiras móveis.

\subsubsection{Barreiras Fixas}

São consideradas barreiras fixas todas as unidades localizadas em pontos estratégicos de maneira permanente com atuação de 24 horas e de forma ininterrupta, com a presença de médicos veterinários, de auxiliares técnicos, com apoio policial, conforme sua classificação.

a) Barreiras Interestaduais

São barreiras fixas, localizadas nas divisas estaduais, para fiscalizar o trânsito de animais, seus produtos e subprodutos, em conformidade com a legislação sanitária vigente.

- Corredor sanitário:

São rotas pré-determinadas para o trânsito de animais, seus produtos e subprodutos, controlados por barreiras fixas localizadas nas divisas estaduais, em conformidade com a legislação sanitária vigente.

- Barreiras com autorização de ingresso:

São barreiras fixas, localizadas nas divisas interestaduais, para fiscalizar o trânsito de animais, seus produtos e subprodutos, em conformidade com a legislação sanitária vigente.

- Barreiras interestaduais com limitação de ingresso:

São barreiras fixas localizadas nas divisas interestaduais para fiscalizar e ou restringir o trânsito de animais, seus produtos e subprodutos, em conformidade com a legislação sanitária vigente. 
b) Barreiras Intraestaduais ou Internas

São barreiras fixas com atuação de 24 horas, localizadas estrategicamente no Estado, para fiscalizar o trânsito de animais, seus produtos e subprodutos, em conformidade com a legislação sanitária vigente.

Todas as barreiras deverão ser compostas basicamente por médico veterinário responsável, auxiliar técnico e com apoio policial, compatível com o fluxo de movimentação.

\subsubsection{Barreiras Móveis}

São consideradas barreiras móveis todas as ações de fiscalizações realizadas em pontos estratégicos, com duração e horários pré-determinados, com a presença de médicos veterinários, auxiliares técnicos e apoio policial, sempre que se fizerem necessárias para atender denúncias ou situações estratégicas e/ou de emergência.

\subsubsection{Barreiras Emergenciais}

Estas barreiras serão implantadas quando da ocorrência de um episódio sanitário grave que justifique a sua instalação, em quantidade e pelo tempo necessário para conter o mesmo, adotando-se as medidas sanitárias necessárias. Sua estrutura básica será composta de médico veterinário como coordenador das barreiras implantadas, auxiliar técnico, com apoio policial, compatível com o fluxo de movimentação.

A sua atuação fiscalizadora será determinada através de normativas emitidas pela autoridade competente, conforme a situação sanitária objeto da sua implantação. 


\section{MATERIAIS E MÉTODOS}

Realizaram-se visitas semanais. Por se tratar de uma indústria de grande porte, a disponibilização para a coleta era feita em horários limitados resultando, desta forma, que as coletas foram realizadas em um lote por coleta no período de junho à setembro de 2012, em um matadouro-frigorífico de suínos no Rio Grande do Sul, sob inspeção federal (SIF).

Amostraram-se trezentas meias carcaças, nas áreas de pernil, lombo e papada, ao final do processo de abate, utilizando-se suabes friccionado dez vezes em áreas de $10 \mathrm{~cm}^{2}$, com acondicionamento individual de cada coleta ( 2 suabes por meia carcaça nas 3 regiões). Os suabes foram depositados no interior de um tubo com tampa de rosca contendo $9 \mathrm{~mL}$ de água peptonada $1 \%$ tamponada, sendo encaminhado para o laboratório de microbiologia da ULBRA e processados no mesmo dia.

Para o isolamento de Salmonella, realizou-se a incubação do suabe em água peptonada a $37^{\circ} \mathrm{C}$ durante $24 \mathrm{~h}$; após, transferiu-se $0,1 \mathrm{~mL}$ de inóculo para 9,9 $\mathrm{mL}$ de caldo Rappaport-Vassiliadis (Oxoid) e 0,5mL para 9,5 mL caldo Selenito Cistina (Oxoid), os quais foram incubados a $42^{\circ} \mathrm{C}$, por $24 \mathrm{~h}$. Posteriormente, uma alçada foi semeada, por esgotamento, em placas com ágar XLD (Oxoid), incubadas à $37^{\circ} \mathrm{C}$, por 24 h. Após, colônias de coloração negra ou da cor do meio foram repicadas para ágar Sangue (AS) e ágar MacConkey (MC) e classificadas por testes bioquímicos (presença de motilidade no Meio de SIM e a ausência de urease no Caldo de Uréia). Nas colônias suspeitas, realizou-se o teste de aglutinação em lâmina, com soro polivalente para Salmonella, para confirmação de gênero.

Utilizou-se análise descritiva, registrando-se a frequência do isolamento de salmonelas. 


\section{RESULTADOS E DISCUSSÃO}

Das trezentas meias carcaças analisadas, isolaram-se salmonelas em sete $(0,017 \%)$,nas seguintes regiões:pernil,lombo e papada.Embora em estudos anteriores tenha sido observada maior prevalência de animais portadores de salmonelas ao abate - variando 55 a 85\% (BESSA et al., 2004; SCHWARZ et al., 2009), bem como superfícies de carcaças positivas - 11,7\% (LIMA et al., 2004), a implantação de programas de controle deste microrganismo em unidades produtivas e na indústria de beneficiamento, têm resultado na diminuição na frequência de isolamentos de salmonelas na espécie suína.

Algumas diferenças de resultados observadas nesta pesquisa quando comparadas com a literatura, em relação às variações da contaminação em diversos segmentos do processo de abate de suínos podem ser justificadas pela variação das condições de higiene operacional e pessoal, de equipamentos e das instalações vigentes em cada estabelecimento, revelando a complexidade das atividades de abate. Por isso, diferentes etapas podem se constituir em variados PCC's, em função da estrutura de abate de cada estabelecimento.

Entretanto, deve-se considerar que os processos particularmente envolvidos no risco de contaminação por Salmonella sp no abate de suínos são a evisceração e a toalete, mas o escaldamento e a divisão da carcaça também podem introduzir microrganismos que resultam em uma maior contaminação ao fim da linha do abate (THORBERG \& ENGVALL, 2001).

A possibilidade de contaminação microbiana da superfície da carcaça de suínos em um matadouro é ampla, tanto por bactérias deterioradoras quanto por patogênicas. O processo de abate inclui algumas operações nas quais o número de bactérias pode diminuir, mas não inclui nenhuma etapa capaz de eliminá-las totalmente (RIVAS et al., 2000).

Por outro lado, o aumento da incidência de salmonelose em casos de infecção de origem alimentar está associado ao aumento da população, ao aumento da criação e alimentação de animais com o uso de antibióticos, ao aumento do consumo de carnes e derivados, à preparação maciça de alimentos, ao armazenamento inadequado e ao hábito crescente do consumo de produtos crus e mal cozidos (BARRETO, 2001).

A qualidade da matéria-prima, a padronização do processamento e a manutenção das temperaturas na saída da indústria até as gôndolas do supermercado têm sido citadas como parâmetros importantes para se evitar cada vez mais frequentes toxinfecções alimentares. A busca incessante da qualidade, seja na produção, transporte, armazenamento e consumo de 
alimentos é fator primordial na competição entre empresas deste mercado (RICHARDS, 2003).

A legislação estabelecida pelo Ministério da Agricultura Pecuária e Abastecimento com a Portaria $n^{\circ} 46$ de 10 de fevereiro de 1998 (BRASIL, 1998), determinou a implantação paulatina do sistema APPCC nas indústrias de produtos de origem animal. No Brasil, somente alguns frigoríficos já possuem o sistema APPCC implantado ou estão em fase de implantação, principalmente os estabelecimentos exportadores revelando, assim, a necessidade de pesquisas que subsidiem a implantação desse programa de garantia de qualidade nos estabelecimentos de abate de suínos. Portanto, é possível concluir que a redução do nível de carcaças contaminadas na indústria será alcançada pela identificação e controle das fontes de contaminação em todos os estágios de produção.

Medidas adotadas para melhorias no sistema de produção pode-se citar:

- Melhorias nas instalações de abate;

- Descrição do Manual de Procedimentos Padrão de Higiene (PPHO), Pré-Operacional e Operacional, com posterior treinamento de supervisores e colaboradores do setor;

- Intensificação nas medidas de BPF e mais rigidez dos monitores de check-list;

- Resolução das deficiências detectadas pelos check-list com mais agilidade;

- Início da implantação da APPCC.

Segundo Schwarz et al. (22009), o controle da infecção por Salmonella spp. no sul do Brasil deve iniciar-se pela implementação de medidas de profilaxia nas granjas de produção de suínos.

Em uma primeira análise, a vacinação dos animais integrados não será a solução para reduzir a contaminação por Salmonella spp no frigorífico avaliado, pois a mistura com lotes de granjas diferentes e com suínos de terceiros, irá favorecer a contaminação cruzada. Se acaso, o frigorífico fosse autossuficiente, com os animais oriundos apenas de suas granjas e se os caminhões de transporte também fossem de uso exclusivo, seria favorável realizar testes de vacinação dos animais para avaliação da sua eficácia. 


\section{CONCLUSÃO}

Os resultados observados indicam uma boa execução durante todos os processos de abate, resultando em um baixo percentual de contaminação por Salmonella spp na fase final do abate. 


\section{REFERÊNCIAS BIBLIOGRÁFICAS}

BARROS, V. R. M.; PAVIA, P. C.; PANETTA, J. C. Salmonella spp: sua transmissão através dos alimentos. Higiene Alimentar, v.16, n.94, p.15-19, 2002.

BEnITEZ, L. B. Monitoramento de Pontos Críticos de Controle (PCCs) no Abate de Frangos através de Indicadores Microbiológicos. Dissertação (Mestrado em Ciência e Tecnologia dos Alimentos)- Universidade Federal de Santa Maria, Santa Maria, 2000.

BERENDS, B. R.; KNAPEN, F.; SNIJDERS, J. M. A. \& MOSSEL, D. A. A. Identification and quantification of risk factors regarding Salmonella spp on pork carcasses. International Journal Food Microbiology, v. 36, n.2/3, p.199--206, 1997.

BERENDS, B. R.; KNAPEN F.; MOSSEL, D. A. A.; Burt S. A. \& Snijders J. M. A. Impact on human health of Salmonella spp on pork in the Netherlands and the anticipated effects of some currently proposed control strategies. International Journal of Food Microbiology, v.44, n.3, p. 219--229, 1998.

BESSA, M.C.; COSTA, M.; CARDOSO, M. Prevalência de Salmonella sp em suínos abatidos em frígoríficos do Rio Grande do Sul. Pesquisa Veterinária Brasileira. v.24, n.2, p. 80-84, 2004.

BRASIL. Portaria SVS/MS n³26 de 30 de julho de 1997. Estabelece o Regulamento Técnico sobre as Condições Higiênico-Sanitárias e de Boas Práticas de Fabricação para Estabelecimentos Produtores/Industrializadores de Alimentos. Diário Oficial da União, 01 de agosto de 1997. Seção 1. Disponível em: <http://www.anvisa.gov.br/legis/portarias/326_97.htm>. Acesso em: 12/03/2013.

BRASIL, Ministério da Agricultura, Pecuária e Abastecimento. Sanidade Animal.Disponível em: 〈http://www.agricultura.gov.br/animal/sanidade-animal $>$. Consultado dia 28/01/2013. 
FRANCO, B. M. F.; LANDGRAF, M. Microbiologia dos alimentos. São Paulo: Atheneu, 1996. $182 \mathrm{p}$.

LIMA, E.S.C. de; PINTO, P.S.A.; SANTOS, J.L.; VANETTI, M.C.D.; BEVILACQUA, P.D.; ALMEIDA, L.P.; PINTO, M.S.; DIAS, F.S. Isolamento de Salmonella sp e Staphylococcus aureus no processo do abate suíno como subsídio ao sistema de Análise de Perigos e Pontos Críticos de Controle - APPCC. Pesquisa Veterinária Brasileira. v.24, n.4, p.185-190, 2004.

MADEIRA, M.; FERRÃO, M.E.M. Alimentos conforme a lei. São Paulo: Manole, 2002. $443 p$.

PARDI, M. C.; SANTOS, I. F. dos; SOUZA, E. R. de; PARDI, H. S. Ciência, Higiene e Tecnologia da Carne. Volume 2., Goiânia:UFG, 1993.1110p.

RICHARDS, N. S. P. S. Segurança Alimentar- Como prevenir contaminações na indústria. Food Ingredients,São Paulo:Ano III,n.18,p.16- 30, 2003.

SCHWARZ, P.; CALVEIRA, J.; SELLA, A.; BESSA, M.; BARCELLOS, D.E.S.N.; CARDOSO, M. Salmonella enterica: isolamento e soroprevalência em suínos abatidos no Rio Grande do Sul. Arquivo Brasileiro de Medicina Veterinária e Zootecnia. v.61, n.5, p.10281034, 2009.

TERRA, N. N. Apontamentos de Tecnologia de Carnes. São Leopoldo: Unisinos, 1998, $216 p$. 
